\title{
Effects of autumn-winter Arctic sea ice on winter Siberian High
}

\author{
WU BingYi*, SU JingZhi \& ZHANG RenHe \\ Chinese Academy of Meteorological Sciences, Beijing 100081, China
}

Received March 31, 2011; accepted July 18, 2011

\begin{abstract}
The intensity of the winter Siberian High has significantly negative correlations with Arctic sea ice concentration anomalies from the previous autumn to winter seasons in the Eastern Arctic Ocean and Siberian marginal seas. Our results indicate that autumn-winter Arctic sea ice concentration and concurrent sea surface temperature anomalies are responsible for the winter Siberian High and surface air temperature anomalies over the mid-high latitudes of Eurasia and East Asia. Numerical experiments also support this conclusion, and consistently show that the low sea ice concentration causes negative surface air temperature anomalies over the mid-high latitudes of Eurasia. A mechanism is proposed to explain the association between autumn-winter sea ice concentration and winter Siberian High. Our results also show that September sea ice concentration provides a potential precursor for winter Siberian High that cannot be predicted using only tropical sea surface temperatures. In the last two decades (1990-2009), a strengthening trend of winter Siberian High along with a decline trend in surface air temperature in the mid-high latitudes of the Asian Continent have favored the recent frequent cold winters over East Asia. The reason for these short-term trends in winter Siberian High and surface air temperature are discussed.
\end{abstract}

Arctic sea ice, Siberian High, East Asian climate, frequent cold winter

Citation: Wu B Y, Su J Z, Zhang R H. Effects of autumn-winter Arctic sea ice on winter Siberian High. Chinese Sci Bull, 2011, 56: 3220-3228, doi: 10.1007/s11434-011-4696-4

Ongoing global warming has resulted in Arctic warming and summer sea ice reductions. This trend has been evident particularly since the rapid declines in summer Arctic sea ice starting in the late 1990s. Decreases in Arctic sea ice have enhanced Arctic warming [1,2], and affected climate variation far away through positive/negative feedbacks on the atmosphere [3-8]. Recently, Eurasia has experienced frequent cold winters and extreme snowfall/rainfall events, as well as Arctic sea ice reductions. Previous studies have indicated that the Eurasian frequent cold winters are closely associated with decreases in autumn-winter Arctic sea ice $[9,10]$. Francis et al. [11] showed that September sea ice extent is associated with large-scale atmospheric circulation anomalies during winter. Honda et al. [8] further indicated that significant cold anomalies over the Far East in early winter and zonal cold anomalies from Europe to the Far East in late winter are associated with a decrease in Arctic

\footnotetext{
*Corresponding author (email: wby@ cams.cma.gov.cn)
}

sea ice in the previous September, which tends to strengthen the Siberian High (SH). Observational evidence has shown that a winter heavy sea ice in the Barents-Kara seas is associated with less cold air activities in China and weakened East Asian winter monsoon [9]. These results have been supported by the simulation experiments of Petoukhov and Semenov [10].

Winter SH significantly influences East Asian climate $[12,13]$, and its intensity can be regarded as an independent index of East Asian winter monsoon (EAWM) variability [14]. Because the winter SH is associated with cold air activities originating from northern high latitudes and North Atlantic Oscillation (NAO)/Arctic Oscillation (AO), it provides a connection between the Arctic and East Asian climate variations [15,16]. Results from $\mathrm{Wu}$ et al. [14] may imply that tropical sea surface temperature (SST) anomalies cannot be regarded as reliable indicators to predict the $\mathrm{SH}$. Thus, this study aims to provide a method to predict the winter SH. In addition, this research investigates the possi- 
ble reason for the recent frequent cold winters. Specifically, we stress the connection between autumn-winter Arctic sea ice and the winter SH. We show that the September Arctic sea ice concentration (SIC) provides a precursor for the winter $\mathrm{SH}$, and a short-term strengthening of winter mean SLP in northern Eurasia is responsible for the recent frequent cold winters.

It should be noted that this study differs from several previous studies [8-11]. Francis et al. [11] did not investigate the association between Arctic September sea ice and the winter SH. Based on observations and simulations with prescribed Arctic SICs, Honda et al. [8] explored lag effects of September SICs on atmospheric circulation and they stressed the effects on air temperature in early winter (December) and late winter (February) (see their Figure 2) and on sea level pressure in particular November and December months (see their Figure 3). Thus, Honda et al. [8] also did not investigate effects of September sea ice on the winter SH. Through sensitivity experiments with prescribed SICs, Petoukhov and Semenov [10] investigated the influence of decreased winter SICs in the Barents-Kara seas on winter circulation. Balmaseda et al. [17] suggested that the effect of Arctic sea ice on the atmosphere strongly depends on SSTs. In addition, they suggested that atmospheric sensitivity to sea ice anomalies under climatological or idealized SST conditions may not be relevant to assess the effect of sea ice anomalies in specific years. Consequently, in forecasting, it is necessary to consider the combined effects of both sea ice and SSTs on the atmosphere.

\section{Data}

The data used in this study include: the Arctic SIC dataset $\left(1^{\circ} \times 1^{\circ}\right)$ for the period from 1979 to May 2010, obtained from the British Atmospheric Data Centre (BADC, http://badc. nerc.ac.uk/data/hadisst/); the monthly mean sea level pressure (SLP), surface air temperature (SAT) and the $500 \mathrm{hPa}$ geopotential height from 1979 to June 2010, obtained from NCEP/NCAR re-analysis I and Japanese Re-analysis (JRA-25) data (http://ds.data.jma.go.jp/gmd/jra/download/data/MonthFinal/anl_p25/) [18]; the monthly mean SST $\left(2^{\circ} \times 2^{\circ}\right)$ from 1979 to May 2010 (http://dss.ucar.edu/datasets/ds277.0/) [19]; the monthly mean SLP data at three stations (Fuyun: $46.59^{\circ} \mathrm{N}, 89.31^{\circ} \mathrm{E}$; Tieganlike: $40.38^{\circ} \mathrm{N}, 87.42^{\circ} \mathrm{E}$; Aershan: $47.10^{\circ} \mathrm{N}, 119.45^{\circ} \mathrm{E}$ ) in China for the period 1979-2009, supplied by the Meteorological Information Center of China; the monthly mean snow water equivalent (SWE) data obtained from National Snow and Ice Center from 1979 to May 2007 (http://nsidc.org/data/nsidc-0271.html) [20], and converted to $1^{\circ} \times 1^{\circ}$ grids; and the land air temperature anomalies on a $5^{\circ}$ by $5^{\circ}$ grid-box basis from 1979 to October 2010 (http://www.cru.uea.ac.uk/cru/data/temperature/).

In this study, we used the regional-averaged $\left(40^{\circ}-60^{\circ} \mathrm{N}\right.$, $80^{\circ}-120^{\circ} \mathrm{E}$ ) winter (December-February) SLP as the intensity index of the $\mathrm{SH}$, as previously described by $\mathrm{Wu}$ and Wang [16]. Additionally, the ECHAM5 [21] model (T63 spectral resolution and 19 pressure levels) was applied to explore effects of both SIC and SST on the atmosphere. The experiments were performed using observed 30-year (19782007) monthly mean SST and SIC as the forcing with 12 different atmospheric initial conditions.

\section{Associations between Arctic SIC and Winter SH: Implications for seasonal prediction}

The $\mathrm{SH}$ is associated with the spatial evolution of autumnwinter Arctic SIC anomalies, as shown in Figure 1. In September, significant negative SIC anomalies were observed in the Eastern Arctic, from the northern Barents Sea to the northern Laptev Sea and northern Eastern Siberian Sea (Figure 1(a)). In October, significant SIC anomalies appeared in the northern Barents Sea and from the Kara Sea to the Eastern Siberian Sea, which shifted southward relative to those in September (Figure 1(b)). The spatial distribution

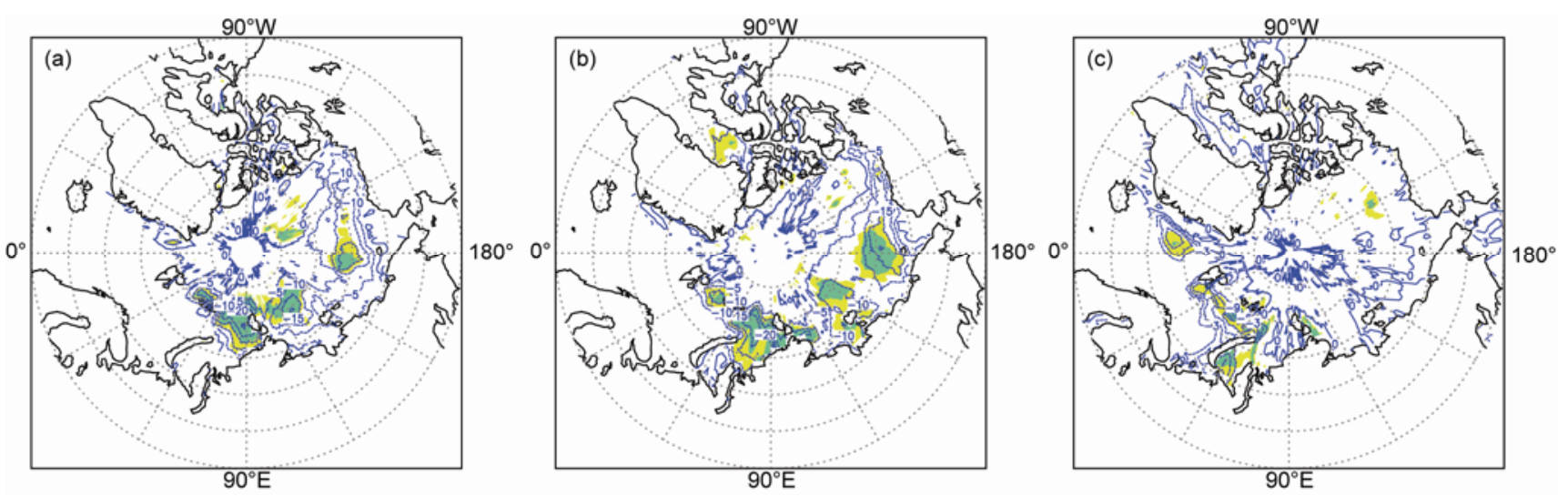

Figure 1 (a) Regression maps of previous September SIC on the ensuing winter SH intensity index derived from the JRA re-analysis data. The yellow and green areas denote SIC anomalies exceeding the $95 \%$ and $99 \%$ significance levels, respectively, (b) and (c), the same as in (a), but for the previous October and winter, respectively. 
of autumn (October-November) SIC anomalies associated with the SH closely resembled those in October (not shown). In winter, significant negative SIC anomalies were mainly confined to the eastern Greenland Sea and the Barents-Kara seas (Figure 1(c)). In fact, the regional-averaged $\left(76.5^{\circ}-\right.$ $\left.83.5^{\circ} \mathrm{N}, 60.5^{\circ}-149.5^{\circ} \mathrm{E}\right)$ September SIC was significantly correlated with the winter SIC in the Barents-Kara seas $\left(67.5^{\circ}-80.5^{\circ} \mathrm{N}, 20.5^{\circ}-80.5^{\circ} \mathrm{E}\right)(r=0.66$, the correlation was 0.52 after removing their trends). This indicated that the spatial evolution of SIC anomalies exhibited coherent features from autumn to winter. Such coherency provides a possibility for predicting the SH. Figure 1(c) implies that if there were light SICs in the Barents-Kara seas, both the $\mathrm{SH}$ and EAWM would be strengthened. This is consistent with previous studies $[9,10]$. The regional-averaged September SIC was significantly correlated with the SH $(r=-0.65$, after removing their trends, the correlation was -0.60) (Figure 2). September SIC reached record lows in 1995, 2005, and 2007, and the corresponding SH indices exceeded one standard deviation, indicating a strong EAWM influencing East Asian countries.

To explore the spatial structure of atmospheric circulation anomalies associated with autumn-winter SIC anomalies, a composite analysis was performed. According to the time series of the regional-averaged September SIC shown in Figure 2, we selected heavy and light SIC cases. This criterion had a standard deviation of $>0.7$ or $<-0.7$. Thus, the heavy SIC cases included 1980, 1981, 1986, 1988, 1989, 1992, 1996, 1998 and 2003, and the light SIC cases were 1991, 1995, 1999, 2005, 2007, 2008 and 2009. Figure 3 shows the differences between the heavy and light SIC cases. Significant negative SLP anomalies occupied northern Eurasia, and there was a negative anomalous center close to the Barents-Kara seas (Figure 3(a)). Such a spatial distribution of winter SLP anomalies favors more than normal sea ice exports into the Greenland-Barents seas, which is consistent with the results shown in Figures 1(c) and 2. Thus, heavy autumn SIC cases correspond to a weaker SH relative to light SIC cases. At the surface, positive SAT anomalies appeared over the mid-high latitudes of Eurasia and East Asia with negative SAT anomalies over most of the Arctic

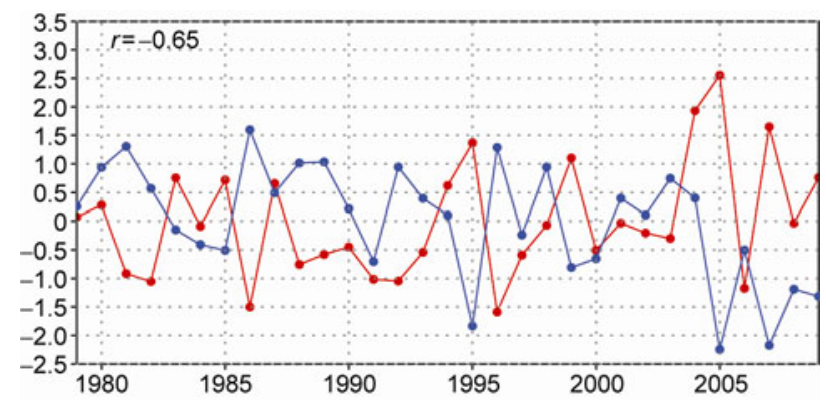

Figure 2 Normalized time series of the winter SH intensity index derived from JRA re-analysis data (red) and the previous September regionalaveraged $\left(76.5^{\circ}-83.5^{\circ} \mathrm{N}, 60.5^{\circ}-149.5^{\circ} \mathrm{E}\right)$ SIC (blue).
Ocean, the Greenland-Barents-Kara seas, and northern North Atlantic (Figure 3(b)). Significant negative SAT anomalies over the Greenland-Barents-Kara seas reflected a direct effect of sea ice. The spatial distribution of winter SAT anomalies was dynamically consistent with anomalous surface winds (not shown). Southerly anomalies caused positive SAT anomalies over the Asian Continent, while northerly anomalies over the Greenland-Barents seas resulted in lower SAT and increased sea ice exports. At $500 \mathrm{hPa}$, height differences exhibited a teleconnection pattern with three anomalous centers over Western Europe, the Barents Sea, and south of Baikal (Figure 3(c)). These results imply that if there are heavy autumn SICs in the Eastern Arctic from the northern Barents Sea to the northern Laptev Sea, positive SAT anomalies over East Asia and weakened SH and EAWM would be expected in the following winter. Likewise, very similar results derived from NCEP/NCAR re-analysis data were also observed (not shown).

In fact, Arctic SIC anomalies were concurrent with SST anomalies. In September, compared with light SIC cases, heavy SIC cases corresponded to colder SSTs in the North Atlantic, northern and northwestern Pacific, and Arctic Eurasian marginal seas (Figure 3(d)). Similar results were observed in autumn (Figure 3(e)). In winter, significant negative SST anomalies mainly occurred in the East Asian marginal seas, the northern North Atlantic, and the Greenland-Barents seas (Figure 3(f)). Thus, to simulate the observed winter SLP and SAT anomalies over Eurasia, we used realistic SST and SIC data as the forcing from 1978 to 2007 with 12 different atmospheric initial conditions. Each experiment includes 9 heavy (1980, 1981, 1986, 1988, 1989, 1992, 1996, 1998, and 2003) and 4 light (1991, 1995, 1999, and 2005) SIC cases (Figure 2, its standard deviation of $>0.7$ or $<-0.7)$. Simulated differences in winter mean SAT between heavy and light SIC cases (heavy: 108 cases; light: 48 cases) are shown in Figure 3(g). Compared with light SIC cases, heavy SIC cases resulted in weak positive SAT anomalies over Europe and East Asia, with significant negative SAT anomalies over the North Atlantic, Northern Pacific, and Eurasian marginal seas. The largest negative SAT anomalies emerge over the Greenland-Barents seas, reflecting the effect of sea ice on SAT. In contrast to these observations (Figure 3(a)), the simulated differences in winter mean SLP show positive SLP anomalies over most of northern Eurasia (not shown). Such a discrepancy is reasonable, because the large-scale response depends on interactions between the anomalous surface fluxes associated with SST and SIC forcing, and the large-scale circulation (or initial conditions) [3,4]. Additionally, other processes, such as Eurasian snow cover, also influenced atmospheric circulation. A further analysis indicated that there were only four experiments that, to a great extent, could capture the observed winter SLP and SAT anomalies. Thus, we only analyzed the four experiments, as shown in Figure 3(h) and (i). Compared with light SIC cases, heavy SIC cases lead to 

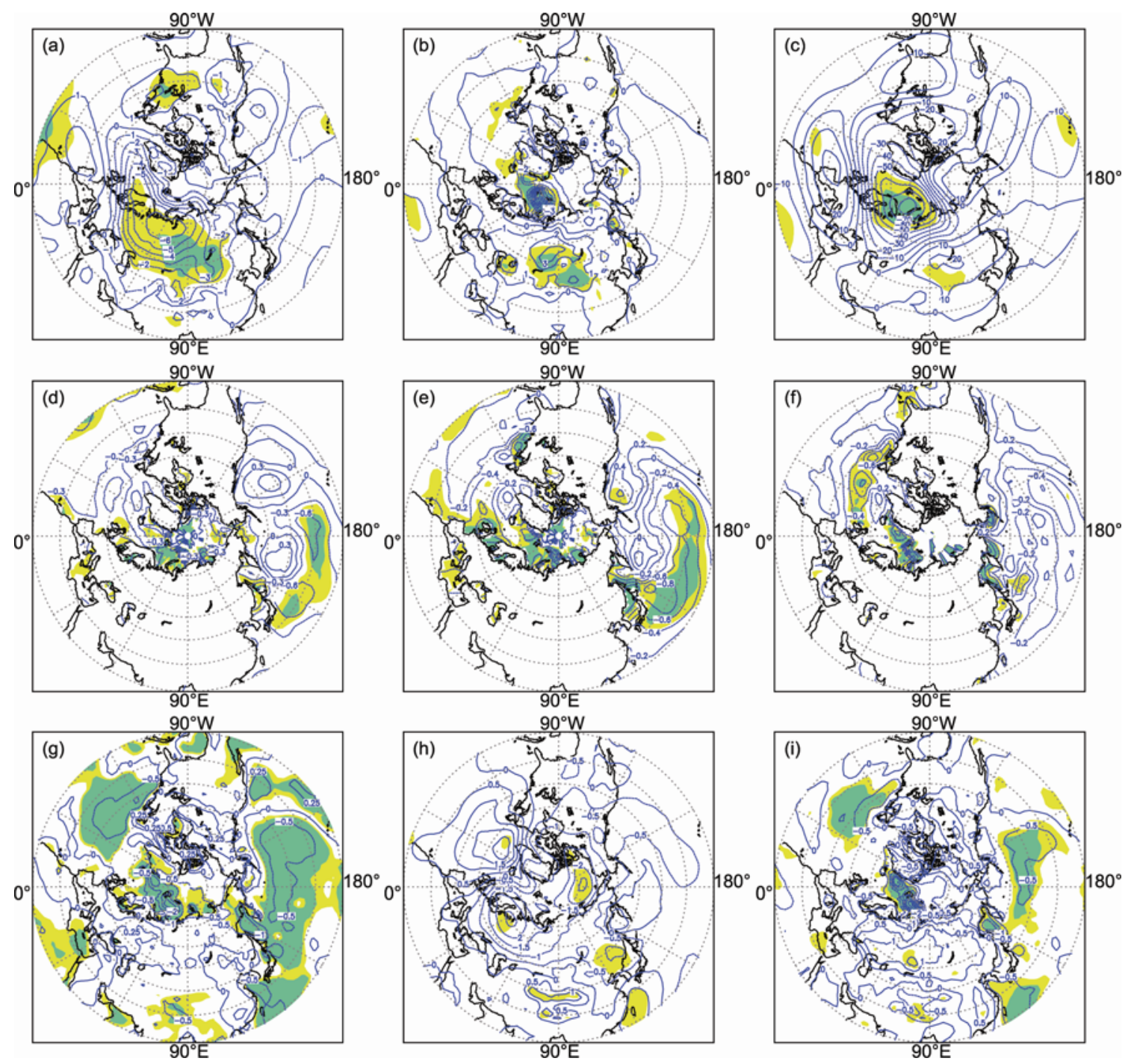

Figure 3 (a) Differences in winter mean SLP between heavy (1980, 1981, 1986, 1988, 1989, 1992, 1996, 1998, and 2003) and light (1991, 1995, 1999, 2005, 2007, 2008, and 2009) September SIC cases, derived from JRA re-analysis data, (b) and (c) are the same as in (a), but for SAT and $500 \mathrm{hPa}$ heights, respectively, (d)-(f) are the same as in (a) except for SST differences in (d) September, (e) autumn and (f) winter, (g) differences in the winter mean SAT between heavy $(1980,1981,1986,1988,1989,1992,1996,1998$, and 2003) and light (1991, 1995, 1999, and 2005) September SIC derived from 12 experiments with the realistic SIC and SST as the forcing during 1978 to 2007; (h) and (i) are the same as in (g) except for winter SLP and SAT, respectively, derived from four experiments. The yellow and green areas denote differences exceeding the $95 \%$ and $99 \%$ significance levels, respectively.

negative SLP anomalies over northern Eurasia and the entire Arctic, indicating a positive phase of the winter AO. Meanwhile, positive SAT anomalies were observed over northern Eurasia and East Asia, which is consistent with observations shown in Figure 2(a). On the other hand, all experiments consistently showed that light SIC cases resulted in negative SAT anomalies over the mid-high latitudes of Eurasia (not shown). The experimental results imply that the effects of both autumn-winters SIC and SST on winter SAT are robust. Thus, September SIC provided a precursor for predicting the SH and EAWM.

To further analyze winter atmospheric circulation anomalies associated with the previous September SIC, a linear regression analysis was performed on the de-trended September SIC, as shown in Figure 4. It is evident that negative
SLP anomalies occurred in northern Eurasia, and there was an anomalous center over northern Europe (Figure 4(a)), resembling the composite analysis shown in Figure 3(a). At the surface, negative SAT anomalies were mainly confined to the Nordic-Barents-Kara seas with concurrent positive SAT anomalies over the mid-high latitudes of Eurasia, East Asia and its marginal seas (Figure 4(b)). Significant positive SAT anomalies occurred over East Asia and part of the northwestern Pacific, differing from those in Figure 3(b). Results here are consistent with the simulations of Alexander et al. [3], who showed that the feedback of Arctic sea ice on the atmosphere is negative in the Atlantic sector. In other words, the large-scale response to reduced (enhanced) winter sea ice extent to the east (west) of Greenland resembles the negative phase of the AO or NAO, reflecting indirect 


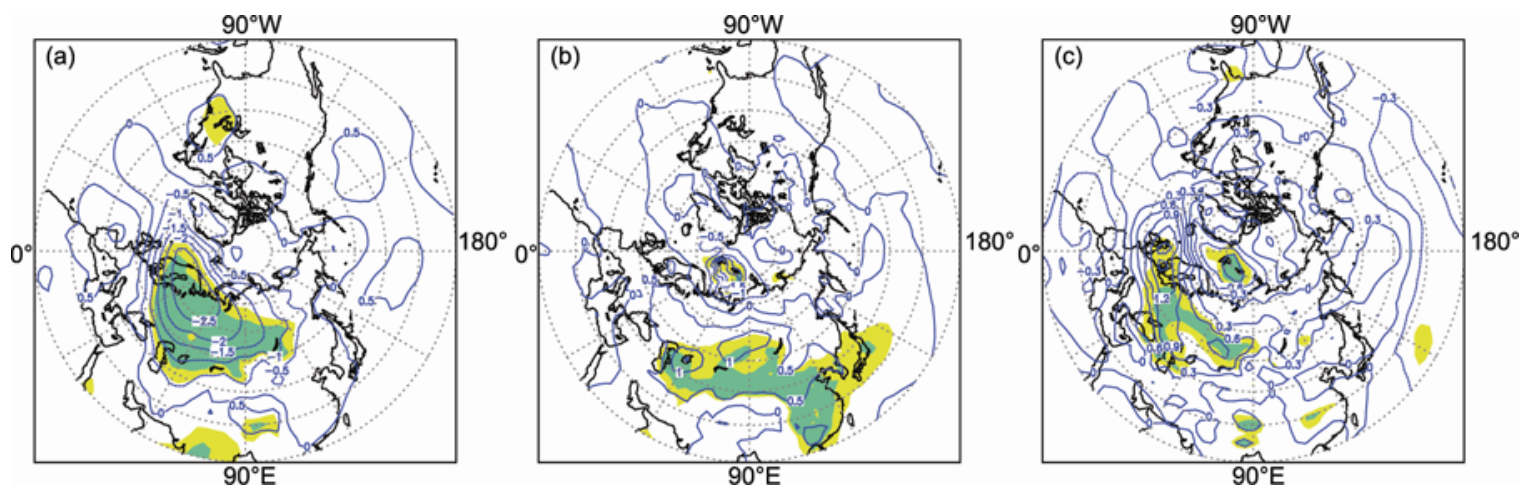

Figure 4 Regression maps of winter mean (a) SLP, (b) SAT, and (c) $850 \mathrm{hPa}$ zonal winds of JRA re-analysis data, derived from a regression on the de-trended regional-averaged September SIC. The yellow and green areas denote anomalies at the $95 \%$ and $99 \%$ significance levels, respectively.

effects of sea ice on the atmosphere. Petoukhov and Semenov [10] showed that anomalous decreases in winter SIC in the Barents-Kara seas result in extreme cold winters. Thus, numerical experiments by Honda et al. [8] and Petoukhov and Semenov [10] also support our results.

A mechanism is proposed to explain the association between autumn-winter SIC and winter SH/East Asian climate. Through the negative feedback process, a successive autumnwinter heavy SIC in the Eastern Arctic and the GreenlandBarents-Kara seas (opposing to Figure 1) and concurrent negative SST anomalies (particularly in the northern North Atlantic) (Figure 3(d)-(f)) cause winter negative SLP anomalies over northern Eurasia and the northern North Atlantic (Figure 4(a)). These anomalies lead to a weakened SH and strengthened westerlies over the mid-high latitudes of Eurasia. A regression analysis of winter $850 \mathrm{hPa}$ winds also confirmed this suggestion (Figure 4(c)). Furthermore, the autumn-winter heavy SIC results in negative air temperature anomalies over the Arctic and strengthened atmospheric thermal gradients between the Arctic and the mid-high latitudes of Eurasia, which also strengthens the westerlies over northern Eurasia. The strengthened westerlies obstruct cold air breaking out southward from high latitudes, leading to positive SAT anomalies over the mid-high latitudes of Eurasia and East Asia.

\section{Trend of winter SH over the past two decades}

Although the SH index derived from NCEP/NCAR reanalysis data is coherent with that derived from JRA reanalysis data (their correlation was 0.9 ), their trends were different during the study period. A positive trend in JRA data and a small declining trend in NCEP/NCAR data were observed (both are not statistically significant; not shown). Their 5-year running means exhibited coherent rising trends since 1990, as shown in Figure 5. Averaged winter SLP at three stations in China (Fuyun: $46.59^{\circ} \mathrm{N}, 89.31^{\circ} \mathrm{E}$; Tieganlike: $40.38^{\circ} \mathrm{N}, 87.42^{\circ} \mathrm{E}$; Aershan: $47.10^{\circ} \mathrm{N}, 119.45^{\circ} \mathrm{E}$ ) also displayed a similar evolution. It seems that JRA re-analysis

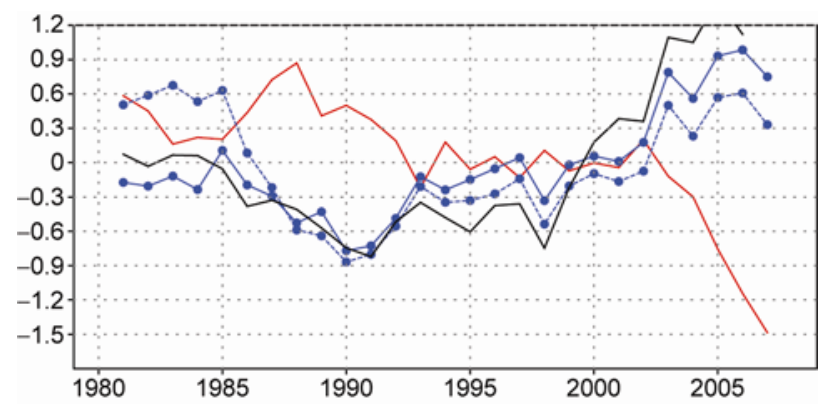

Figure 5 Five-year running means of the normalized time series: winter SH intensity indices. Solid blue: JRA data; dashed blue: NCEP/NCAR data), winter mean SLP at three Chinese stations (black), and the regional-averaged September SIC (red).

data were closer to observations relative to NCEP/NCAR data. Thus, we only investigated the spatial distribution of trends in climate variations over the past two decades (19902009).

Winter SLP showed rising trends in high-latitudes, and large trends $(>0.3 \mathrm{hPa})$ appeared over the area from southeast Greenland northeastward to northern Eurasia (Figure 6(a)). Regionally, the largest trends occurred in the Barents Sea and the southern Kara Sea, where the winter regional-averaged SLP $\left(65^{\circ}-75^{\circ} \mathrm{N}, 20^{\circ}-80^{\circ} \mathrm{E}\right)$ had a stronger rising trend after 1990, relative to the SH. Conversely, there was a decreasing trend prior to 1990 (not shown). SLP decline trends were observed in the mid-low latitudes of Eurasia, northern Africa, and the North Atlantic. The anomalous anticyclone (not shown) associated with a strengthening of winter SLP resulted in decreasing trends of SAT over the northern Asian Continent, north of $40^{\circ} \mathrm{N}$. Regionally, the largest negative trends appeared in west of Baikal (Figure 6(b)). Significant SAT warming trends also were found from northeastern United States to Greenland, and extending to the Laptev Sea, with its center over the Barents Sea.

Positive trends in $500 \mathrm{hPa}$ heights covered most of the Arctic region and part of northern Eurasia, whereas negative trends occurred in the mid-high latitudes of East Asia (Figure 6(c)). Similar results also were observed in NCEP/ 

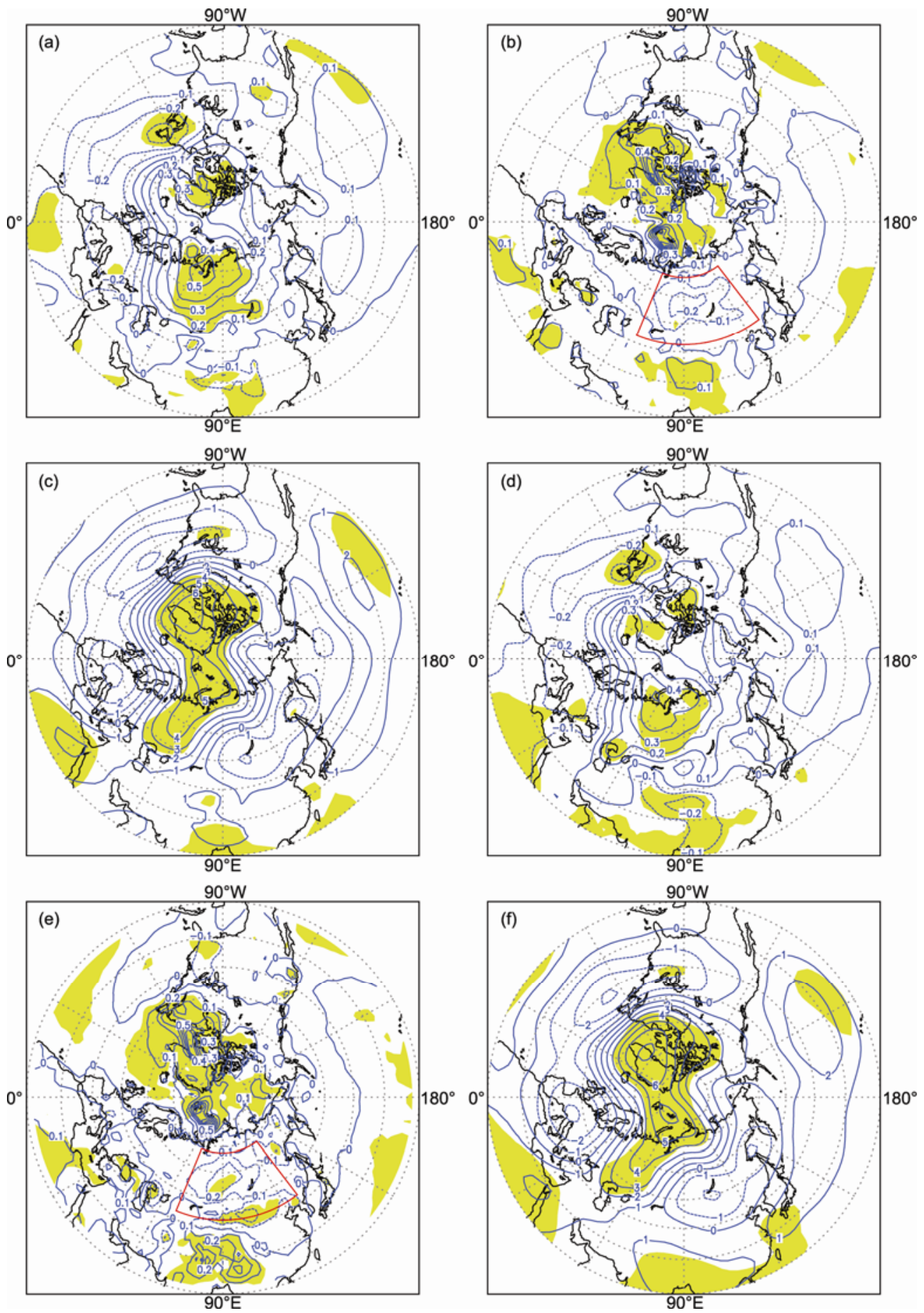

Figure 6 Spatial distribution of winter (a) SLP, (b) SAT, and (c) $500 \mathrm{hPa}$ height trends during the period from 1990 to 2009 derived from JRA re-analysis data. Shaded areas represent trends at the 95\% significance levels, (d)-(f) are the same as that in (a)-(c), but derived from NCEP/NCAR re-analysis data.

NCAR re-analysis data (Figure 6(d)-(f)). Compared with Figure 6(b), SAT decreasing trends are significant in the midhigh latitudes of the Asian Continent (Figure 6(e)). The regional-averaged winter SAT anomalies derived from observations, JRA and NCEP/NCAR re-analysis data also showed a coherent decreasing trend after 1990 (Figure 7), which is consistent with the strengthening trend of winter
SH. Consequently, such a climate trend background has favored recent frequent cold winters over Eurasia. Deser and Phillips [22] investigated winter atmospheric circulation trends from 1950 to 2000, and they showed that coherent SLP decreasing trends occurred in the entire Arctic and the mid-high latitudes of Eurasia (implying a weakening of SH, see their Figure 1), which differed from the results of this 


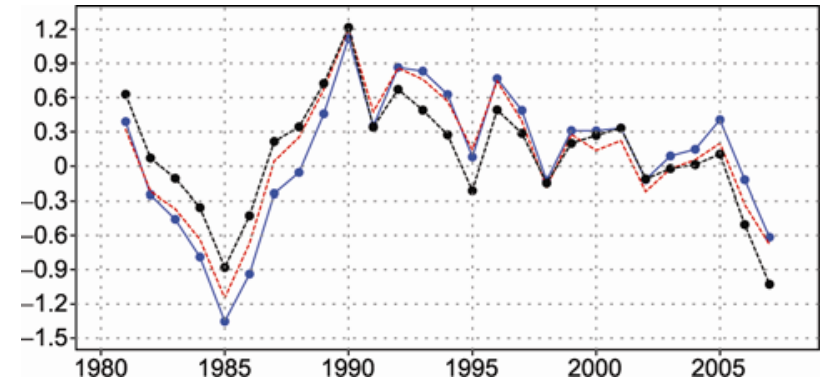

Figure 7 Five-year running means of the regional-averaged $\left(42.5^{\circ}-\right.$ $\left.67.5^{\circ} \mathrm{N}, 67.5^{\circ}-127.5^{\circ} \mathrm{E}\right)$, marked by the red box shown in Figure $6(\mathrm{~b})$ winter SAT anomalies derived from observations (http://www.cru.uea.ac.uk/cru/ data/temperature/)(red line) and JRA re-analysis data (blue line). The black line is the same as the blue line but derived from NCEP/NCAR re-analysis data over the area $42.8564^{\circ}-67.6171^{\circ} \mathrm{N}, 67.5^{\circ}-127.5^{\circ} \mathrm{E}$, marked by the red box in Figure 6(e).

study (i.e. different study periods).

\section{Possible mechanism for identified trends and discussion}

The declining trends in autumn (September-November) SIC were significant in most of the Arctic Ocean and its marginal seas, particularly in the Barents-Kara seas and from the Eastern Siberian Sea eastward to the Beaufort Sea (Figure 8(a)). Significant warming trends in the autumn SST appeared in the North Atlantic and Arctic marginal seas, which is consistent with SIC declining trends (Figure 8(b)). In the North Atlantic, the trends of $>0.04^{\circ}$ mainly were confined within $50^{\circ}-70^{\circ} \mathrm{N}$. SST warming trends at the $99 \%$ significance level corresponded well to SLP trends $>0.3 \mathrm{hPa}$ (Figure 6(a)). In fact, autumn SST also displayed a persistent warming trend after 1990 (Figure 9). The North Atlantic SST anomalies may have a role in forming winter blocking-like anomalies over the Ural Mountains [23], which causes a strengthened winter SH [24]. Additionally, the autumn regional-averaged SWE $\left(40^{\circ}-60^{\circ} \mathrm{N}, 60^{\circ}-140^{\circ} \mathrm{E}\right)$ exhibited an increasing trend after 1990, favoring a strengthening of the SH [25]. Through numerical experiments, Magnusdottir et al. [6] investigated the atmospheric response to trends of winter (December-March) Arctic sea ice extent from 1958 to 1997, and they found that the realistic Arctic sea ice decline trend directly caused positive $500 \mathrm{hPa}$ height anomalies over the entire Arctic, with negative height anomalies over the North Atlantic and the mid-high latitudes of East Asia (see their Figure 3). These patterns are consistent with observations (Figure 6(c),(f)). Additionally, Deser and Phillips [22] demonstrated that with a realistic SST and SIC as the forcing, the simulated winter SLP exhibited coherent positive trends in the Arctic and northern Eurasia, implying a strengthening of the $\mathrm{SH}$ (see their Figure 1).

Most researchers, including ourselves, have considered that atmospheric circulation patterns and centers of action were mainly representative of natural variability. Consequently, the short-term trends in the SH and SAT after 1990 are likely to have been mainly controlled by interdecadal (or multidecadal) variability. This hypothesis is supported by previous studies [26,27]. Polyakov et al. [27] suggested that Atlantic water temperature, Arctic surface air temperature, sea ice extent and fast ice thickness in the Siberian marginal seas exhibited coherent low-frequency oscillations (LFO) on the time scales of 50-80 years, and that short-term trends are strongly amplified by the LFO. On the other hand, coherent low-frequency fluctuations (or interdecadal variability) in the atmosphere-ocean-ice system in the Arctic and the North Atlantic requires that SIC anomalies have an important effect on the atmosphere [28,29]. Investigating the effect of Arctic sea ice decline trend on atmosphere trends (or interdecadal variability) is beyond the scope of the present study.
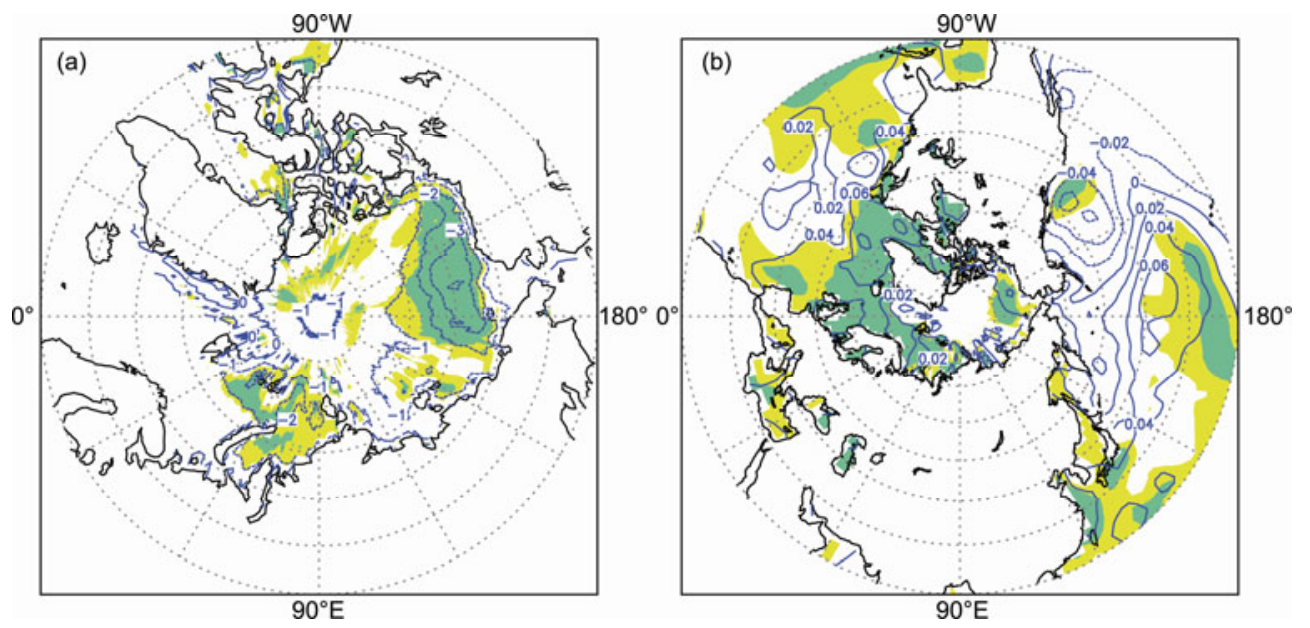

Figure 8 Spatial distribution of autumn (a) SIC and (b) SST trends during the period from 1990 to 2009, with the yellow and green areas representing the trends at the $95 \%$ and $99 \%$ significance levels, respectively. 


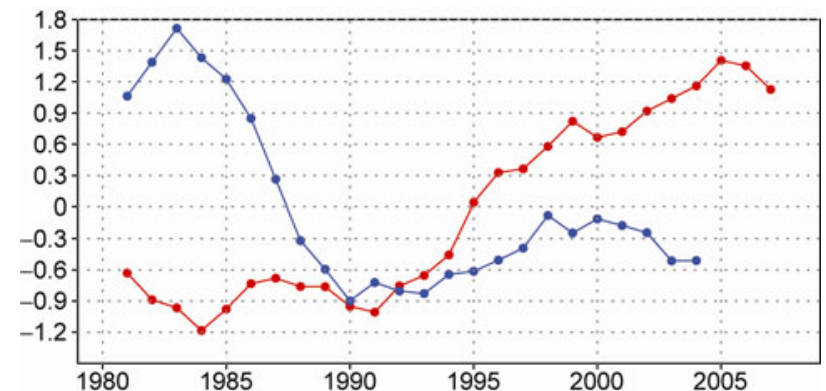

Figure 9 Five-year running means of the normalized regional-averaged autumn SST (red, $48^{\circ}-66^{\circ} \mathrm{N}, 30^{\circ}-60^{\circ} \mathrm{W}$ ) and SWE (blue, $40^{\circ}-60^{\circ} \mathrm{N}$, $\left.60^{\circ}-140^{\circ} \mathrm{E}\right)$.

Through numerical experiments, Deser et al. [5] has shown the response processes of the atmosphere to Arctic sea ice/North Atlantic SST forcing. That is, the initial response of the atmosphere to the combined forcing is baroclinic, and then the response progressively becomes more barotropic and increases in both spatial extent and magnitude. They indicated that the equilibrium stage of the atmospheric adjustment is reached in 2-2.5 months, which is consistent with results from the present study. Clearly, the precise mechanisms responsible for the effects of autumn SICs and SSTs on winter SH and SAT over Asian continent and their relative roles deserve further investigation in the future using observations and simulation experiments.

\section{Conclusions}

The present study investigates the effect of Arctic SIC on the winter SH and SAT over Eurasia through observations and numerical experiments. Our findings indicate that the winter SH intensity index, defined by the regional-averaged SLP, shows significant negative correlations with autumnwinter Arctic SIC in Eastern Arctic and Eurasian marginal seas. The coherent variations in Arctic SIC from autumn to winter provide a possibility for seasonal predictions of the winter SH and EAWM. These results indicate that the combined effects of both autumn-winter Arctic SIC and SST anomalies are responsible for winter SH and SAT anomalies over the mid-high latitudes of Eurasia and East Asia. Numerical experiments also support this conclusion, and consistently show that light SIC cases result in negative SAT anomalies over the mid-high latitudes of Eurasia. Results show that the September Arctic SIC provides a precursor for the winter SH that cannot be predicted using only the tropical SST. In the last two decades (1990-2009), a strengthening trend of the winter SH, along with SAT decreasing trends in the mid-high latitudes of Asia, has favored frequent cold winters over East Asia. The short-term trends have been controlled by interdecadal (or multidecadal) variability in which autumn-winter Arctic SIC and SST may have important roles.
We are thankful to Dr. Liu Ge for providing SLP data from three Chinese stations. We thank two anonymous reviewers for their constructive comments. This work was supported by the National Basic Research Program of China (2007CB411505), the Calling Project of China (GYHY200906017), the National Natural Science Foundation of China (40875052 and 40921003) and the Basic Research Foundation of CAMS (2010Z003).

1 Screen J A, Simmonds I. The central role of diminishing sea ice in recent Arctic temperature amplification. Nature, 2010, 464: 1334-1337

2 Kumar A, Perlwitz J, Eischeid J, et al. Contribution of sea ice loss to Arctic amplification. Geophys Res Lett, 2010, 37: L21701, doi: 10.1029/2010GL045022

3 Alexander M A, Bhatt U S, Walsh J E. The atmospheric response to realistic sea ice anomalies in an AGCM during winter. J Clim, 2004, 17: 890-905

4 Deser C, Magnusdottir G, Saravanan R. The effects of North Atlantic SST and sea ice anomalies on the winter circulation in CCM3. Part II: Direct and indirect components of the response. J Clim, 2004, 17: 877-889

5 Deser C, Tomas R A, Peng S. The transient atmospheric circulation response to North Atlantic SST and sea ice anomalies. J Clim, 2007, 20: 4751-4767

6 Magnusdottir G, Derser C, Saravanan R. The effects of North Atlantic SST and sea ice anomalies in the winter circulation in CCM3. Part I: Main features and storm track characteristics of the response. J Clim, 2004,17: 857-876

7 Honda M, Yamazaki K, Nakamura H, et al. Dynamic and thermodynamic characteristics of atmospheric response to anomalous sea-ice extent in the Sea of Okhotsk. J Clim, 1999, 12: 3347-3358

8 Honda M, Inous J, Yamane S. Influence of low Arctic sea-ice minima on anomalously cold Eurasian winters. Geophys Res Lett, 2009, 36: L08707, doi:10.1029/2008GL037079

9 Wu B Y, Huang R H, Gao D Y. Effects of variation of winter sea-ice area in Kara and Barents seas on East Asian winter monsoon. Acta Meteorol Sin, 1999, 13: 141-153

10 Petoukhov V, Semenov V A. A link between reduced Barents-Kara sea ice and cold winter extremes over northern continents. J Geophys Res, 2010, 115: D21111, doi: 10.1029/2009JD013568

11 Francis J A, Chan W, Leathers D J, et al. Winter north hemisphere weather patterns remember summer Arctic sea-ice extent. Geophys Res Lett, 2009, 36: L07503, doi:10.1029/2009GL037274

12 Ding Y H, Krishnamurti T N. Heat budget of Siberian High and winter monsoon. Mon Weather Rev, 1987, 115: 2428-2449

13 Ding Y H. Build-up, air mass transformation and propagation of Siberian High and its relation to cold surge in east Asia. Meteorol Atmos Phys, 1990, 44: 281-292

14 Wu B Y, Zhang R H, D'Arrigo R. Distinct modes of the East Asian winter monsoon. Mon Weather Rev, 2006, 134: 2165-2179

15 Gong D Y, Wang S W, Zhu J H. East Asian winter monsoon and Arctic Oscillation. Geophys Res Lett, 2001, 10: 2073-2076

16 Wu B Y, Wang J. Winter Arctic Oscillation, Siberian High and East Asian winter monsoon. Geophys Res Lett, 2002, 29, 19: 1897, doi: 10.1029/2002GL015373

17 Balmaseda M, Ferrantic L, Molteni F, et al. Impact of 2007 and 2008 Arctic ice anomalies on the atmospheric circulation: Implications forlong-range predictions. Quart J Roy Meteor Soc, 2010, 136: 1655-1664

18 Onogi K, Tsutsui J, Koide H, et al. The JRA-25 Reanalysis. J Meteorol Soc Jpn, 2007, 85: 369-432

19 Smith T, Reynolds R. Extended reconstruction of global sea surface temperature based on COADS data (1854-1997). J Clim, 2003, 16: 1495-1510

20 Armstrong R L, Brodzik M J, Knowles K, et al. Global monthly EASE-Grid snow water equivalent climatology. Boulder, CO: National Snow and Ice Data Center, 2007, Digital media

21 Roeckner E, Bäuml G, Bonaventura L, et al. The atmospheric general circulation model ECHAM5. Part I: Model description, Rep. 349, 
Max Planck Inst For Meteorol, Hamburg, Germany, 2003

22 Deser C, Phillips A S. Atmospheric circulation trends, 1950-2000: The relative roles of sea surface temperature forcing and direct atmospheric radiative forcing. J Clim, 2009, 22: 396-413

23 Li S. Impact of Northwest Atlantic SST anomalies on the circulation over the Ural Mountains during early winter. J Meteorol Soc Jpn, 2004, 82: 971-988

24 Takaya K, Nakamuta H. Mechanisms of intraseasonal amplification of the cold Siberian High. J Atmos Sci, 2005, 62: 4423-4439

25 Cohen J, Entekhabi D. Eurasian snow cover variability and northern hemisphere climate predictability. Geophys Res Lett, 1999, 26: 345-348
26 Polyakov I, Johnson M. Arctic decadal and interdecadal variability. Geophys Res Lett, 2000, 27: 4097-4100

27 Polyakov I, Alekseev G, Timokhov L, et al. Variability of the intermediate Atlantic water of the Arctic Ocrean over the last 100 years. J Clim, 2004, 17: 4485-4497

28 Mysak L A, Manak D K, Marsden R F. Sea-ice anomalies observed in the Greenland and Labrador Seas during 1901-1984 and their relation to an interdecadal Arctic climate cycle. Clim Dyn, 1990, 5: 111-133

29 Mysak L A, Venegas S A. Decadal climate oscillation in the Arctic: A new feedback loop for atmosphere-ice-ocean interactions. Geophys Res Lett, 1998, 25: 3607-3610

Open Access This article is distributed under the terms of the Creative Commons Attribution License which permits any use, distribution, and reproduction in any medium, provided the original author(s) and source are credited. 